\title{
Evaluadores Número 5, año 3, 2015
}

Dr. José Daniel Rueda Estrada, Universidad de Valladolid, España.

Dr. Norberto Méndez Blanco, Universidad de Buenos Aires, Argentina.

Dra. Rosalia Vofchuk, Universidad de Buenos Aires, Argentina.

Dr. Pablo Zanor, Universidad Nacional de La Matanza, Argentina.

Mag. Norma Alicia del Rio Lugo, Universidad Autónoma Metropolitana, México.

Lic. Maya Alvisa Barroso, Universidad del Salvador, Argentina.

Dra. Denise Benatuil, Universidad de Palermo, Argentina.

Dra. Lía Rodriguez de la Vega, Universidad de Palermo, Argentina. 